\title{
Modelling of Turning Traffic Volume In Ibadan, Nigeria using Linear and Hybrid Furness-Fratar Techniques
}

\author{
O. Joy Oladejo ${ }^{1}$, Ademola A. Dare ${ }^{2}$, O.A. Agbede ${ }^{1}$ \\ 1 Department of Civil Engineering, University of Ibadan, Ibadan, Nigeria. \\ 2 Department of Mechanical Engineering, University of Ibadan, Ibadan, Nigeria.
}

\begin{abstract}
Estimation for inflow and outflow traffic volumes are often carried out manually and electronically. These are used for road design planning and management. The time, labour and financial demand are often high and needed serious consideration. This has thus formed the basis of this work. objective of this work is directed at reducing the time, labour and financial demand associated with traffic volume count. Two new traffic models namely linear lagragian and hybrid furness-fratar models were developed. The models were used to investigate an intersection with five legs at Ibadan, Nigeria. The predicted traffic volume when one of the legs was treated as unknown was compared with the field values. Thereafter turning traffic volumes estimate for all the legs was carried out using furness model.

The model estimates using linear lagragian showed that estimate of leg with least traffic volume are closer to the field values than when legs with high traffic volume were considered. The hybrid furness-fratar model did not give a clearly defined pattern The U- turn traffic volumes for all the legs were less than $0.05 \%$ when compared with the outflow volume. This suggests that U-turn is very unusual at this intersection and should be taken into consideration at any future development.
\end{abstract}

Keywords: Traffic, Turning volume, Furness model, Fratar Model, Hybrid Model

\section{INTRODUCTION}

In Nigeria, road transportation is the dominant form of transportation[1]. As such increasing attention is being required for its management. The demand of traffic engineer is to majorly improve on the efficiency of an existing system rather than to build new higher capacity roads[2]. There were considerable efforts in the development of traffic theories in 1905's.. Some of the seminal works of that period include the works by Newell[3], Webster[4], Edie and Foote[5], Chandler et al[6] and other papers by Herman et al[7]. Turning traffic volumes are important part of the analysis of any intersection, to measure turning traffic volumes, vehicles must be tracked through the intersection from their approach leg to their exit leg. Turning traffic volumes are important part of the analysis of any intersection, to measure turning traffic volumes, vehicles must be tracked through the intersection from their approach leg to their exit leg. Michael et al[8] evaluated that an alternative to directly measuring turning movement volumes through field observations is to estimate them. Bell[9]; Cremer and Keller[10]; Nihan and Davis[11 $]^{11}$ earlier described some turning movement estimation procedures. Adebisi[12] used published algorithms to improve manually counted turning traffic volume at road junctions. Notable models such as furness and fratar models have been developed for estimation of turning traffic volume. These models which can be used to predict reliably turnings at intersections require complete inflow and outflow volumes at each leg of the intersection. Shiliang et.al[13] discussed Markov Chain approach of estimating traffic volume in cases there are missed days. For a city like Ibadan, there may be one leg without information about the inflow and outflow traffic volume. In the light of this, there is the need to develop suitable turning traffic model for cases when there are missing or incomplete information of a leg in an intersection

\section{DESCRIPTION OF STUDY AREA SELECTED INTERSECTIONS}

The models to be developed are expected to be used to carry out traffic study in the city of Ibadan, Nigeria. Ibadan, city in southwestern Nigeria, capital of Oyo State, located about $110 \mathrm{~km}$ (about $70 \mathrm{mi}$ ) northeast of Lagos. Ibadan is a major transit point between the coast and areas to the north. The city is on the railroad line linking Lagos with Kano and is well connected by road to other cities in the region

\section{MULTI-LEG INTERSECTION}

This is a converging point for vehicles coming from the northern and eastern parts of the country and as well as from Lagos, the largest commercial city in Nigeria. A sketch of the intersection is shown in Figure 2 


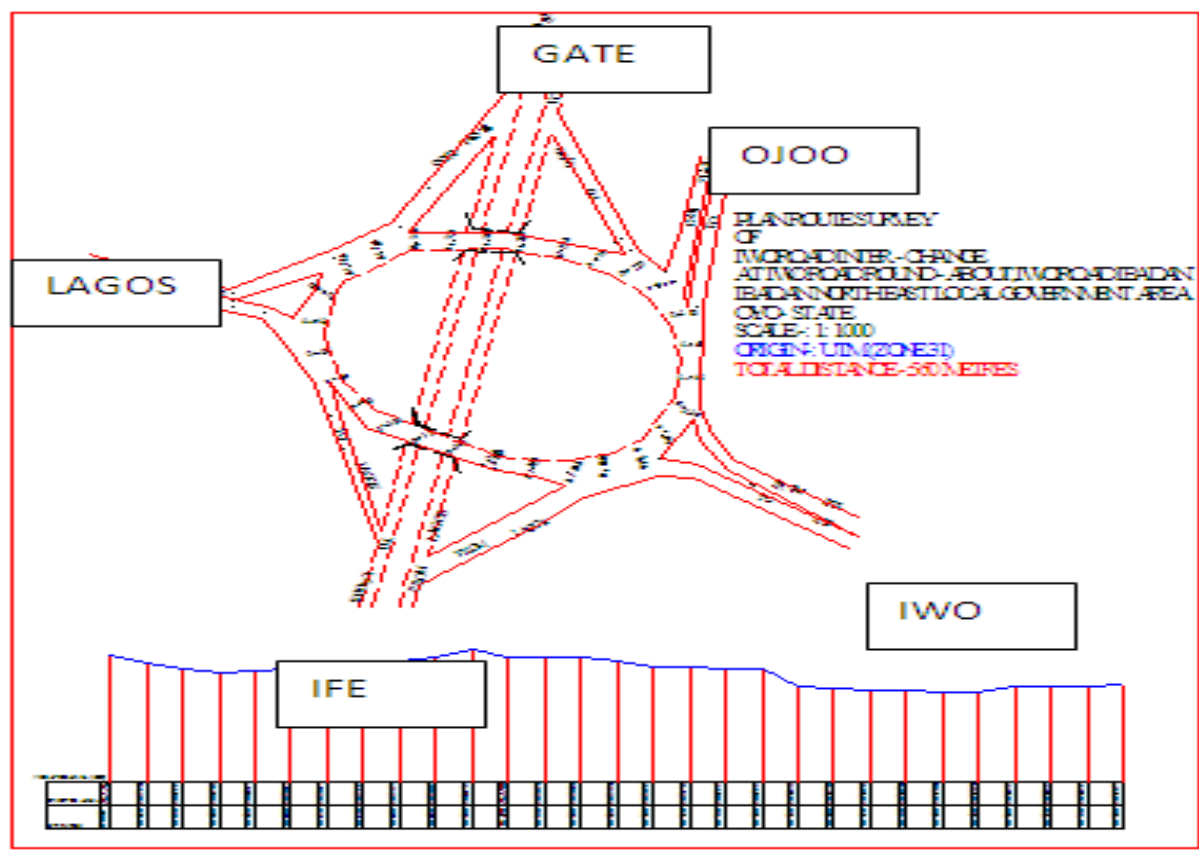

Fig. 1: A Multi Leg Intersection at Iwo road, Ibadan.

\section{Development of Linear and Hybrid Model of Fratar and Furness}

Given a junction with $\mathrm{m}$-legs the inflow and outflow then $\mathrm{x}_{1}, \mathrm{x}_{2} \ldots \ldots \ldots \ldots \ldots \ldots \mathrm{x}_{\mathrm{m}}$ are outflow from each of the legs while $x_{n+1+}, x_{n+2+}$ $\mathrm{x}_{2 \mathrm{~m}}$ are inflow from each of the legs.

Assuming that $\mathrm{t}_{\mathrm{ij}}$ is the turning traffic volume from leg $\mathrm{i}$ to leg $\mathrm{j}$, then the turnings at the junction can be estimated using the furness model stated below.

The Fratar turning traffic equation can be written as

$$
t_{i j}^{n}=t_{i j}^{n-1} G_{i}^{n-1} G_{j}^{n-1}
$$

This equation is recast as

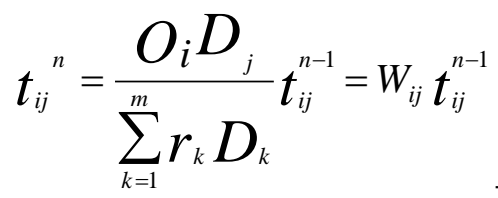

$\mathrm{O}_{\mathrm{i}}=$ inflow into a leg $\mathrm{i}$

$\mathrm{D}_{\mathrm{i}}=$ outflow from a leg $\mathrm{i}$

$$
\text { where } W_{i j}=\frac{O_{i} D_{j}}{\sum_{k=1}^{m} r_{k} D_{k}}
$$

Let $\quad \boldsymbol{O}_{i}=\sum_{k=1}^{2 m} a_{k} \boldsymbol{X}_{k}$ where $\mathrm{a}_{\mathrm{k}}=1$ if $\mathrm{k}=\mathrm{i}$ otherwise $\mathrm{a}_{\mathrm{k}}=0$

and $\quad D_{j}=\sum_{k=1}^{2 m} b_{k} \boldsymbol{X}_{k}$ where $\mathrm{b}_{\mathrm{k}}=1$ if $\mathrm{k}=\mathrm{j}+\mathrm{m}$ otherwise $\mathrm{b}_{\mathrm{k}}=0$

By setting $\mathrm{c}_{\mathrm{i}}=0$ for $\mathrm{i}=1, \mathrm{~m}$

and $c_{i}=r_{j}$ for $i=m+1,2 m$ with $\mathrm{j}=\mathrm{i}-\mathrm{m}$

Then $\quad \sum_{k}^{m} \boldsymbol{r}_{k} \boldsymbol{D}_{k}=\sum_{k=1}^{2 m} \boldsymbol{c}_{l} \boldsymbol{x}_{l}$

Note that for a leg $\mathrm{i}$ in the intersection, the inflow is now being represented as an unknown $\mathrm{x}_{\mathrm{i}}$ while the outflow is represented by $\mathrm{x}_{\mathrm{i}+\mathrm{m}}$ 
Eqns (5) can thus be rewritten as $W_{i j}=\frac{\sum_{k=1}^{2 m} a_{k} \boldsymbol{x}_{k} \sum_{k=1}^{2 m} b_{k} \boldsymbol{X}_{k}}{\sum_{k=1}^{2 m} \boldsymbol{c}_{k} \boldsymbol{x}_{k}}$

An aggregate objective function can be written as $F=\sum_{i=1}^{m} \sum_{j=1}^{m} W_{i j}$

The Furness equation for turning volume are given as

$$
t_{i j}{ }^{n}=\frac{t_{i j}{ }^{n-1} O_{i}}{\sum_{j=1}^{m} t_{j i}^{n-1}}
$$

$$
\boldsymbol{t}_{i j}{ }^{n+1}=\frac{\boldsymbol{t}_{i j}{ }^{n} \boldsymbol{D}_{j}}{\sum_{j=1}^{m} \boldsymbol{t}_{i j}}
$$

Eqns.(5) and (6) can be combined and also recast as

$$
\boldsymbol{t}_{i j}{ }^{n+1}=\frac{D_{j}}{\sum_{k=1}^{m} \boldsymbol{r}_{k j} \boldsymbol{O}_{k}} \boldsymbol{t}_{i j}^{n}=V_{i} \boldsymbol{t}_{i j}^{n}
$$

In this case $V_{i}=\frac{\sum_{k=1}^{2 m} \boldsymbol{a}_{k} \boldsymbol{x}_{k}}{\sum_{k=1}^{2 m} \boldsymbol{b}_{k} \boldsymbol{x}_{k}}$

For this case an objective function $\mathrm{R}$ can be defined as

$$
R=\sum_{i=1}^{m} V_{i}
$$

For leg j with known inflow $O_{j}$ and outflow $D_{j}$, two constraint equations can be written as

$$
G_{i o}=x_{j}-O_{j}
$$

$$
G_{i d}=x_{j+m}-D_{j}
$$

If there are m-1 legs with known inflow and outflow values then aggregate constraint equations can be written as

$$
\begin{aligned}
G_{a} & =\sum_{j=1}^{m-1} x_{j}-O_{j} \\
G_{b} & =\sum_{j=1}^{m-1} x_{j+m}-D_{j}
\end{aligned}
$$

If it assumed that there is no traffic accumulation at the junction then $($ sum of known inflow into a junction $)=($ sum of known outflow into a junction $)$

Additional constraint equation for the leg $\mathrm{m}$ with unknown inflow and outflow can be written as

$G_{c}=x_{m}-x_{2 m}+\sum_{j=1}^{m-1} x_{j}-\sum_{j=1}^{m-1} x_{j+m}$

A Linear Lagragrian function can then be written as

$L_{l}=R+\lambda\left(G_{a}+G_{b}+G_{c}\right)$ 
$\lambda$ is a Lagragian multiplier

$X=(X)-H^{-1} \Delta L_{l}$

where $H=$ Hessian matrix

An hybrid Lagragian function can also be written as $L_{2}=F^{4}+R^{4}+\lambda\left(G_{a}+G_{b}+G_{c}\right)$

With the unknown inflow and outflow values for a leg in the junction determined, the normal Furness turning traffic equations can then used to estimate the turning traffic volumes for all the legs.

Two models were developed using $\mathrm{L}_{1}$ and $\mathrm{L}_{2}$ Lagragians functions and with the same constraints equations to evaluate the inflow and outflow traffic volumes at an unknown leg.

\section{FIELD STUDY}

Traffic count was carried out at the selected intersection in the city. The inflow and outflow traffic volume was determine for all classes of vehicles. The study was carried out for seven days. Thereafter the average daily traffic(ADT) for inflow and outflow for each of the legs of the intersection was determined.

\section{RESULTS AND DISCUSSIONS}

Each of the models was tested on a selected 5 leg intersection by stepping down one leg after the other and subsequently comparing the model values for inflow and outflow with the obtained field values. The results for Model 1 (using Hybrid Lagragian function) are presented in Tables 1-10, while Tables 11-20 are the results for Model 2(Linear Lagragian function). Results from Model 2 showed a decreasing value of error estimates with decreasing values of inflow and outflow traffic volumes at unknown leg. However Model 1 results did not give a clearly defined pattern. It appears that Model 2 gives better estimate of unknown leg traffic volume with least traffic volume in the intersection. Since Model 1 still yielded converging results, it may be used at an intersection, by initially carrying out some trials which can be used to estimate the correction factor required. Turning traffic volumes estimates suggested that the incidence of U-turns are much unlikely in the intersection. In any case the intersection has a large radius which may make U-turns unnecessary.

\section{REFERENCES}

[1]. Kupolati, W.K. . Characterisation of used Asphalt pavement for Road Construction. PhD Thesis Civil Engineering Department, University of Ibadan, Nigeria, 2008.

[2]. Slinn, M.; Matthews, P.; and Guest, P. Traffic Engineering Design - Principles and Practice. Butterworth - Heinemann Publications, 1998

[3]. Newell, G.F. 1955. Mathematical Models for Freely Flowing Highway Traffic. Operations Research 3, $1955,176-186$.

[4]. Webster, F.V. 1958. Traffic Signal Settings. Road Research Technical Paper No. 39. Road Research Laboratory, London, U.K, 1958.

[5]. Edie, L.C. and Foote, R.S. Traffic Flow in Tunnels, Proc. Highway Research Board, 37, 1958, pp.334344.

[6]. Chandler, R.E., Herman, R. and Montroll, E.W. Traffic Dynamics: Studies in Car Following, Opns. Res. 6, 1958,pp. 165-183.

[7]. Herman, R . Technology, Human Interaction, and Complexity: Reflections on Vehicular, 1992.

[8]. Michael, P.D.; Ahmed, A; Michael, Phil. R and Howard, C. Field Evaluation of Roundabout Turning Movement Estimation Procedure Unpublished.

[9]. Bell, M.G.H. Log -Linear Models for the Estimation of Origin-Destination Matrices from Traffic Counts: An Approximation. Proceedings of the Ninth International Symposium on Transportation and Traffic Theory, Delft, Netherlands, VNU Science Press, 1984.

[10]. Cremer, M. and Keller H. A New Class of Dynamic Methods for the Identification of Origin-Destination Flows. Transportation Research 1987, B212:117-132.

[11]. Nihan, N.L. and G.A. Davis. Application of Prediction - Erro Minimization and Maximum Likelihood to Estimate Intersection O-D matrices from Traffic Counts. Transportation Science 23 (2) 1989,77-90.

[12]. Adebisi, O. Improving Manual Counts of Turning Traffic Volumes at road Junctions. Journal of Transportation Engineering, Vol. 113, No. 3, ASCE, 1987

[13]. Shiliang, S; Gouqiang, Y; Changshi, Z. Short Term Traffic Flow Forecasting using Sampling Markov Chain Method with Incomplete data. Intelligent vehicles symposium, IEEE volume issue, 14-17 June 2004, page $437-441$, 
Table 1: Inflow and OutFlow Values for Field and Hybrid Model with Gate leg Unknown

\begin{tabular}{|l|l|l|l|l|l|l|}
\hline & A:(in(model)) & B:(in(field)) & (B-A)/B & D:(out(model)) & E:(out(field)) & (E-D)/E \\
\hline Leg 1 & 12061 & 12061 & .00 & 23190 & 23190 & .00 \\
\hline Leg 2 & 29785 & 29785 & .00 & 14418 & 14418 & .00 \\
\hline Leg 3 & 2873 & 2873 & .00 & 3469 & 3469 & .00 \\
\hline Leg 4 & 4537 & 4537 & .00 & 4283 & 4283 & .00 \\
\hline Leg 5 & 13834 & 6587 & -1.10 & 13842 & 11214 & -.23 \\
\hline
\end{tabular}

\begin{tabular}{|l|c|c|c|c|c|c|c|}
\hline Table 2: Turning Estimate with & \multicolumn{3}{|c|}{ Gate Leg Unknown with Hybrid Model } \\
\hline & leg 1 & leg 2 & leg $\mathbf{3}$ & leg 4 & leg 5 & \% uturn \\
\hline leg 1 & 379 & 19302 & 1309 & 1024 & 7618 & .01 \\
\hline leg 2 & 7696 & 289 & 208 & 1656 & 4105 & .02 \\
\hline leg 3 & 568 & 2882 & 3 & 636 & 757 & .00 \\
\hline leg 4 & 1801 & 238 & 286 & 40 & 984 & .01 \\
\hline leg 5 & 1617 & 7073 & 1067 & 1180 & 371 & .03 \\
\hline
\end{tabular}

Key

Leg 1-lagos

Leg 2-ife

Leg 3-ojoo

Leg 4-iwo

Leg 5-gate

Table 3: Inflow and OutFlow Values for Field and Hybrid Model with Iwo leg Unknown

\begin{tabular}{|l|l|l|l|l|l|l|}
\hline & A:(in(model)) & B:(in(field)) & (B-A)/B & D:(out(model)) & E:(out(field)) & (E-D)/E \\
\hline Leg 1 & 12061 & 12061 & .00 & 23190 & 23190 & .00 \\
\hline Leg 2 & 29785 & 29785 & .00 & 14418 & 14418 & .00 \\
\hline Leg 3 & 2873 & 2873 & .00 & 3469 & 3469 & .00 \\
\hline Leg 4 & 6587 & 6587 & .00 & 11214 & 11214 & .00 \\
\hline Leg 5 & 14888 & 4537 & -2.28 & 14836 & 4283 & -2.46 \\
\hline
\end{tabular}

Table 4: Turning Estimate with Iwo Leg Unknown with Hybrid Model

\begin{tabular}{|l|c|c|c|c|c|c|c|}
\multicolumn{1}{|c|}{ Table 4: Turning Estimate with } & \multicolumn{3}{|c|}{ Iwo Leg Unknown with Hybrid Model } \\
\hline & leg $\mathbf{l}$ & leg 2 & leg $\mathbf{3}$ & leg 4 & leg 5 & \% uturn \\
\hline leg 1 & 303 & 18740 & 1102 & 1439 & 7339 & .01 \\
\hline leg 2 & 6151 & 281 & 175 & 2328 & 3955 & .02 \\
\hline leg 3 & 454 & 2798 & 3 & 895 & 729 & .00 \\
\hline leg 4 & 3768 & 606 & 630 & 147 & 2482 & .02 \\
\hline leg 5 & 1385 & 7360 & 963 & 1778 & 383 & .03 \\
\hline
\end{tabular}

Key

Leg 1-lagos

Leg 2-ife

Leg 3-ojoo

Leg 4-gate

Leg 5-iwo

Table 5: Inflow and OutFlow Values for Field and Hybrid Model with Ojoo leg Unknown

\begin{tabular}{|l|l|l|l|l|l|l|}
\hline & A:(in(model)) & B:(in(field)) & (B-A)/B & D:(out(model)) & E:(out(field)) & (E-D)/E \\
\hline Leg 1 & 12061 & 12061 & .00 & 23190 & 23190 & .00 \\
\hline Leg 2 & 29785 & 29785 & .00 & 14418 & 14418 & .00 \\
\hline Leg 3 & 4537 & 4537 & .00 & 4283 & 4283 & .00 \\
\hline Leg 4 & 6587 & 6587 & .00 & 11214 & 11214 & .00 \\
\hline Leg 5 & 15131 & 2873 & -4.27 & 15098 & 3469 & -3.35 \\
\hline
\end{tabular}

Table 6: Turning Estimate with Ojoo Leg Unknown with Hybrid Model

\begin{tabular}{|l|c|c|c|c|c|c|c|}
\hline & leg $\mathbf{1}$ & leg 2 & leg $\mathbf{3}$ & leg 4 & leg 5 & \% uturn \\
\hline leg 1 & 300 & 18258 & 1730 & 1388 & 7371 & .01 \\
\hline leg 2 & 6085 & 273 & 275 & 2246 & 3972 & .02 \\
\hline leg 3 & 555 & 3366 & 6 & 1065 & 904 & .00 \\
\hline leg 4 & 3727 & 590 & 989 & 142 & 2493 & .02 \\
\hline leg 5 & 1394 & 7298 & 1538 & 1746 & 392 & .03 \\
\hline
\end{tabular}




Key
Leg 1-lagos
Leg 2-ife
Leg 3-iwo
Leg 4-gate
Leg 5-ojoo

Table 7: Inflow and OutFlow Values for Field and Hybrid Model with Ife leg Unknown

\begin{tabular}{|l|c|c|c|c|c|r|}
\hline & A:(in(model)) & B(in(field)) & (B-A)/B & D:(out(model)) & E:(out(field)) & (E-D)/E \\
\hline Leg 1 & 12061 & 12061 & .00 & 23190 & 23190 & .00 \\
\hline Leg 2 & 2873 & 2873 & .00 & 3469 & 3469 & .00 \\
\hline Leg 3 & 4537 & 4537 & .00 & 4283 & 4283 & .00 \\
\hline Leg 4 & 6587 & 6587 & .00 & 11214 & 11214 & .00 \\
\hline Leg 5 & 7866 & 29785 & .74 & 7680 & 14418 & .47 \\
\hline
\end{tabular}

Table 8: Turning Estimate with Ife Leg Unknown with Hybrid Model

\begin{tabular}{|c|c|c|c|c|c|c|c|}
\hline & leg 1 & leg 2 & leg 3 & leg 4 & leg 5 & $\%$ uturn \\
\hline leg 1 & 1044 & 3938 & 4286 & 4434 & 9489 & .04 \\
\hline leg 2 & 2149 & 6 & 69 & 727 & 518 & .00 \\
\hline leg 3 & 1143 & 429 & 8 & 2013 & 688 & .00 \\
\hline leg 4 & 7574 & 74 & 1429 & 265 & 1872 & .02 \\
\hline leg 5 & 2286 & 741 & 1793 & 2624 & 237 & .03 \\
\hline
\end{tabular}

Key

Leg 1-lagos

Leg 2-ojoo

Leg 3-iwo

Leg 4-gate

Leg 5-ife

Table 9: Inflow and OutFlow Values for Field and Hybrid Model with Lagos leg Unknown

\begin{tabular}{|l|l|l|l|l|l|l|}
\hline & A:(in(model)) & B:(in(field)) & (B-A)/B & D:(out(model)) & E:(out(field)) & (E-D)/E \\
\hline Leg 1 & 29785 & 29785 & .00 & 14418 & 14418 & .00 \\
\hline Leg 2 & 2873 & 2873 & .00 & 3469 & 3469 & .00 \\
\hline Leg 3 & 4537 & 4537 & .00 & 4283 & 4283 & .00 \\
\hline Leg 4 & 6587 & 6587 & .00 & 11214 & 11214 & .00 \\
\hline Leg 5 & 12474 & 12061 & -.03 & 12553 & 23190 & .46 \\
\hline
\end{tabular}

Table 10: Turning Estimate with Lagos Leg Unknown

\begin{tabular}{|c|c|c|c|c|c|c|}
\hline & leg 1 & leg 2 & leg 3 & leg 4 & leg 5 & \% uturn \\
\hline leg 1 & 1501 & 1675 & 1769 & 1818 & 8409 & .10 \\
\hline leg 2 & 3818 & 3 & 35 & 368 & 567 & .00 \\
\hline leg 3 & 2619 & 291 & 5 & 1315 & 971 & .00 \\
\hline leg 4 & 12803 & 37 & 693 & 128 & 1949 & .01 \\
\hline leg 5 & 9043 & 866 & 2035 & 2958 & 578 & .04 \\
\hline
\end{tabular}

Key

Leg 1-ife

Leg 2-ojoo

Leg 3-iwo

Leg 4-gate

Leg 5-lagos 
Table 11: Inflow and OutFlow Values for Field and Linear Model with Gate leg Unknown

\begin{tabular}{|c|c|c|c|c|c|c|}
\hline & A(in(model)) & B:(in(field)) & $(\mathrm{B}-\mathrm{A}) / \mathrm{B}$ & $\mathrm{D}:($ out(model)) & $\mathrm{E}:($ out(field)) & $(E-D) / E$ \\
\hline Leg 1 & 12061 & 12061 & .00 & 23190 & 23190 & .00 \\
\hline Leg 2 & 29785 & 29785 & .00 & 14418 & 14418 & .00 \\
\hline Leg 3 & 2873 & 2873 & .00 & 3469 & 3469 & .00 \\
\hline $\operatorname{Leg} 4$ & 4537 & 4537 & .00 & 4283 & 4283 & .00 \\
\hline Leg 5 & 1693 & 6587 & .74 & 1701 & 11214 & .85 \\
\hline
\end{tabular}

Table 12: Turning Estimate with Gate Leg Unknown with Linear Model

\begin{tabular}{|c|c|c|c|c|c|c|}
\hline & g 1 & $\operatorname{leg} 2$ & leg 3 & leg 4 & leg 5 & $\%$ uturm \\
\hline $\log 1$ & 429 & 2.4381 & 1941 & 132 & 955 & 81 \\
\hline $\log 2$ & 8722 & 365 & 309 & 21.46 & 515 & 03 \\
\hline $\operatorname{leg} 3$ & 644 & 3640 & 5 & $8: 25$ & 95 & 00 \\
\hline $\log 4$ & 2040 & 301 & 424 & 32 & 123 & 02 \\
\hline $\log 5$ & 225 & 1008 & 194 & 188 & 6 & .60 \\
\hline
\end{tabular}

Key

Leg 1-lagos

Leg 2-ife

Leg 3-ojoo

Leg 4-iwo

Leg 5-gate

Table 13: Inflow and OutFlow Values for Field and Linear Model with Iwo leg Unknown

\begin{tabular}{|c|c|c|c|c|c|c|}
\hline & $A($ in $($ model $))$ & B:(in(field)) & $(\mathrm{B}-\mathrm{A}) / \mathrm{B}$ & D:(out(model)) & E:(out(field)) & $(\mathrm{E}-\mathrm{D}) / \mathrm{E}$ \\
\hline Leg 1 & 12061 & 12061 & .00 & 23190 & 23190 & .00 \\
\hline Leg 2 & 29785 & 29785 & .00 & 14418 & 14418 & .00 \\
\hline Leg 3 & 2873 & 2873 & .00 & 3469 & 3469 & .00 \\
\hline $\operatorname{Leg} 4$ & 6587 & 6587 & .00 & 11214 & 11214 & .00 \\
\hline Leg 5 & 1936 & 4537 & .57 & 1883 & 4283 & .56 \\
\hline
\end{tabular}

Table 14: Turning Estimate with Iwo Leg Unknown with Linear Model

\begin{tabular}{|c|c|c|c|c|c|c|}
\hline & & leg 2 & leg 3 & $\operatorname{leg} 4$ & $\operatorname{leg} 5$ & $\%$ uturn \\
\hline $\operatorname{leg} 1$ & 272 & 1034 & 1261 & $15: 2$ & 790 & .01 \\
\hline leg 2 & 8949 & 4.69 & 324 & 3987 & 689 & .03 \\
\hline $\operatorname{leg} 3$ & 328 & 2316 & 3 & -60 & 63 & .00 \\
\hline $\operatorname{leg} 4$ & 7368 & 1359 & 1567 & 339 & 581 & .03 \\
\hline leg $:$ & 198 & 1206 & 175 & 299 & 7 & .00 \\
\hline
\end{tabular}

Key

Leg 1-lagos

Leg 2-ife

Leg 3-ojoo

Leg 4-gate

Leg 5-iwo

Table 15: Inflow and OutFlow Values for Field and Linear Model with Ojoo leg Unknown

\begin{tabular}{|lcccccr|}
\hline & A:(in(model)) & B:(in(field)) & (B-A)/B & D:(out(model)) & E:(out(field)) & (E-D)/E \\
\hline Leg 1 & 12061 & 12061 & .00 & 23190 & 23190 & .00 \\
Leg 2 & 29785 & 29785 & .00 & 14418 & 14418 & .00 \\
Leg 3 & 4537 & 4537 & .00 & 4283 & 4283 & .00 \\
Leg 4 & 6587 & 6587 & .00 & 11214 & 11214 & .00 \\
\hline Leg 5 & 1935 & $\mathbf{2 8 7 3}$ & $\mathbf{3 3}$ & $\mathbf{1 9 0 2}$ & $\mathbf{3 4 6 9}$ & .45 \\
\hline
\end{tabular}


Table 16: Turning Estimate with Ojoo Leg Unknown with Linear Model

\begin{tabular}{|c|c|c|c|c|c|c|}
\hline & & $\operatorname{leg} 2$ & $\operatorname{leg} 3$ & leg , 4 & $\operatorname{leg} 5$ & $\%$ uturn \\
\hline 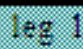 & 268 & $18=11$ & 1979 & $1.15:$ & 777 & .01 \\
\hline leg & 8912 & $4: 8$ & 515 & 38.48 & 684 & .03 \\
\hline 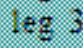 & 412 & 2860 & 5 & $9: 26$ & 79 & .00 \\
\hline $\operatorname{lig}_{2}$ & 6824 & $1: .36$ & 2312 & 30.1 & 537 & .03 \\
\hline lif: & 192 & $1.11: 1$ & 271 & 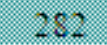 & 6 & .00 \\
\hline
\end{tabular}

Key

Leg 1-lagos

Leg 2-ife

Leg 3-iwo

Leg 4-gate

Leg 5-ojoo

Table 17: Inflow and OutFlow Values for Field and Linear Model with Ife leg Unknown

\begin{tabular}{|c|c|c|c|c|c|c|}
\hline & $A($ in $($ model $))$ & B:(in(field)) & $(B-A) / B$ & D:(out(model)) & $\mathrm{E}$ :(out(field)) & (E-D)/E \\
\hline Leg 1 & 12061 & 12061 & .00 & 23190 & 23190 & .00 \\
\hline Leg 2 & 2873 & 2873 & .00 & 3469 & 3469 & .00 \\
\hline $\operatorname{Leg} 3$ & 4537 & 4537 & .00 & 4283 & 4283 & .00 \\
\hline $\operatorname{Leg} 4$ & 6587 & 6587 & .00 & 11214 & 11214 & .00 \\
\hline Leg 5 & 1114 & 29785 & .96 & 928 & 14418 & .94 \\
\hline
\end{tabular}

Table 18: Turning Estimate with Ife Leg Unknown with Linear Model

\begin{tabular}{|c|c|c|c|c|c|c|}
\hline & $\operatorname{leg} 1$ & $\operatorname{leg} 2$ & $\operatorname{leg} 3$ & $\operatorname{leg} 4$ & $\operatorname{leg} 5$ & $\%$ uturn \\
\hline$=2$ & 2398 & 4820 & 6453 & $=862$ & 1657 & .10 \\
\hline $\operatorname{leg} 2$ & 2664 & : & 56 & 696 & 49 & .00 \\
\hline $\log 3$ & 1642 & $3: 8$ & 8 & 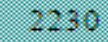 & 75 & .00 \\
\hline $\log 4$ & 9547 & 50 & 1180 & 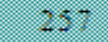 & 179 & .02 \\
\hline $\log 5$ & 360 & 62 & 185 & 310 & 3 & .00 \\
\hline
\end{tabular}

Key

Leg 1-lagos

Leg 2-ojoo

Leg 3-iwo

Leg 4-gate

Leg 5-ife

Table 19: Inflow and OutFlow Values for Field and Linear Model with Lagos leg Unknown

\begin{tabular}{|c|c|c|c|c|c|c|}
\hline & $A:(i n(\operatorname{model}))$ & B:(in(field)) & $(\mathrm{B}-\mathrm{A}) / \mathrm{B}$ & D:(out(model)) & $\mathrm{E}:($ out(field)) & $(\mathrm{E}-\mathrm{D}) / \mathrm{E}$ \\
\hline $\operatorname{Leg} 1$ & 29785 & 29785 & .00 & 14418 & 14418 & .00 \\
\hline Leg 2 & 2873 & 2873 & .00 & 3469 & 3469 & .00 \\
\hline Leg 3 & 4537 & 4537 & .00 & 4283 & 4283 & .00 \\
\hline Leg 4 & 6587 & 6587 & .00 & 11214 & 11214 & .00 \\
\hline Leg 5 & 1179 & 12061 & .90 & 1258 & 23190 & .95 \\
\hline
\end{tabular}

Table 20: Turning Estimate with Lagos Leg Unknown with Linear Model

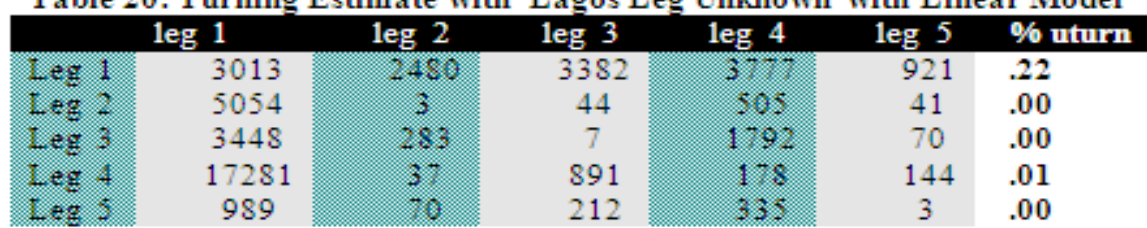

Key

Leg 1-ife

Leg 2-ojoo

Leg 3-iwo

Leg 4-gate

Leg 5-lagos 